\title{
Urethanes and polyurethanes from suberin: 1. Kinetic study
}

\author{
Nereida Cordeiro ${ }^{\mathrm{a}}$, Mohamed Naceur Belgacem ${ }^{\mathrm{b}}$, Alessandro Gandini ${ }^{\mathrm{b}, *}$, \\ Carlos Pascoal Neto ${ }^{\mathrm{c}}$ \\ a Departamento de Química, Universidade de Madeira, 9000 Funchal, Portugal \\ ${ }^{\mathrm{b}}$ Ecole Française de Papeterie et des Industries Graphiques (INPG), BP 65, 38402 St Martin d'Hères, France \\ c Departamento de Quimica, Universidade de Aveiro, 3800 Aveiro, Portugal
}

Received 4 September 1996; accepted 21 November 1996

\begin{abstract}
Within the context of a study on the preparation and the characterization of polyurethanes based on suberin, as a polyol, and conventional polyisocyanates, it was deemed necessary to carry out a preliminary study on the reactivity of the hydroxy functions of suberin. Aliphatic and aromatic mono- and di-isocyanates were tested and the kinetics of this system followed the classical second order up to conversions of about $85 \%$. The influence of the steric hindrance and the electronic factors, linked to the specific structures of both types of isocyanates, was established. (C) 1997 Elsevier Science B.V.
\end{abstract}

Keywords: Suberin; Urethane and polyurethanes; Isocyanates; Reaction kinetics

\section{Introduction}

Cork from Quercus suber L. is a renewable material which has found many industrial applications. Its transformation into different commodities is accompanied by the inevitable accumulation of powder or dust-like by-products which are usually burned for energy recovery. An alternative

\footnotetext{
* Corresponding author. Tel.: + 33 476826947; fax: + 33 476826933; e-mail: Alessandro.Gandini@efpg.inpg.fr
}

use of this fraction calls upon specific treatments in order to produce chemicals, such as suberin (Pereira, 1988), which is the most abundant component of cork, reaching up to $50 \%$ of the dry natural product. The chemical structure of suberin was first studied in detail by Kolattukudy (1978) who examined samples from various vegetal sources and proposed a macromolecular network containing phenolic groups, long aliphatic chains with one or more unsaturations and hydroxy and ester functions. 
In situ, suberin is therefore insoluble in all solvents, but alkaline alcoholysis (Arno et al., 1981) generates oligomeric $C_{16}-C_{26}$ chains bearing carboxylic ester and hydroxy moieties (Holloway, 1972; Agullô and Seone, 1981, 1982) and of course, phenolic derivatives. To the best of our knowledge, the former products have never been exploited as macromonomers to elaborate polymeric materials, although some work was carried out in the 60 's on the specific use of a minor suberin fraction consisting of aliphatic dicarboxylic acids in the synthesis of polyesters (Fontan Yanes and Garzon Sanchez, 1961). Within the more general context of our research interest in the elaboration of novel polymeric materials from renewable resources (Gandini, 1992), we decided to investigate in a more systematic way the possible role of the oligomeric fraction arising from the alcoholysis of suberin as macromonomer. The prevailing structure of these oligomeric fragments is (Cordeiro et al., 1997).<smiles>COC(=O)CCCCCCCCC(O)C(O)CCCCCCCC(=O)OC</smiles>

The presence of hydroxy groups in this fraction, hereafter referred to as 'suberin', constitutes a logical starting point for its utilization as macromonomer in the synthesis of polyesters, polyethers and polyurethanes by the corresponding polycondensation reactions with carboxylic acids, halides and isocyanates. We started with the latter system and this paper reports a first kinetic study on the condensation between suberin and different mono- and di-isocyanates.

\section{Experimental}

Except for suberin, all the reagents, solvents and catalysts used in this work were commercial products of the highest purity available.

The suberin used in this work was obtained by alkaline alcoholysis of a sample of high-quality reproduction cork from Quercus suber L., kindly supplied by the Champcork Company, which was ground to 60 mesh size grains. This powder was extracted sequentially with dichloromethane, ethanol and water and the residue then hydrolyzed with a methanolic $\mathrm{NaOH}$ solution (Cordeiro et al., 1997). The chloroform-soluble fraction of this alcoholysis product was thoroughly characterized by several methods which included the determination of the hydroxy index by conventional methods. The value of $I_{\mathrm{OH}}$ thus obtained was checked by taking FTIR spectra of reaction mixtures involving the subcrin and variable quantities of phenyl isocyanate, until the end-point at which the $\mathrm{OH}$ peak disappeared and the NCO peak appeared. The two analytical techniques gave results which were in agreement within $\pm 3 \%$. This point was essential for the proper adjustment of the polycondensation stoichiometry.

For the uncatalyzed reactions, the isocyanate was added to a solution of suberin in pure dry tetrahydrofuran (THF). The initial concentration of both reagents was always $0.2 \mathrm{M}$ and the stoichiometric conditions were kept equal to unity, viz. $[\mathrm{NCO}]_{0}=[\mathrm{OH}]_{0}$. For the catalyzed reactions, a $10^{2} \mathrm{M}$ solution of the catalyst (dibutyltin dilaurate, DBTD) in dry THF was prepared and stored in a dry atmosphere. The suberin was dissolved in the catalyst solution before the isocyanate was added under vigorous stirring. The resulting solution was quickly poured into an FTIR liquid cell and thereafter spectra recorded at regular intervals. Between spectra, the cell was kept at the desired constant temperature.

\section{Results and discussion}

The experimental data were inspected according to various kinetic models. The second-order treatment proved systematically the most adequate way of representing the kinetic features of these systems with both mono- and di-isocyanates. Thus:

$$
-\mathrm{d}[\mathrm{NCO}] / \mathrm{d} t=k_{2}[\mathrm{NCO}][\mathrm{OH}]
$$

In our context we always worked with $[\mathrm{NCO}]_{0}=$ $[\mathrm{OH}]_{0}$ and therefore:

$-\mathrm{d}[\mathrm{NCO}] / \mathrm{dt}=\mathrm{k}_{2}[\mathrm{NCO}]^{2}$ 


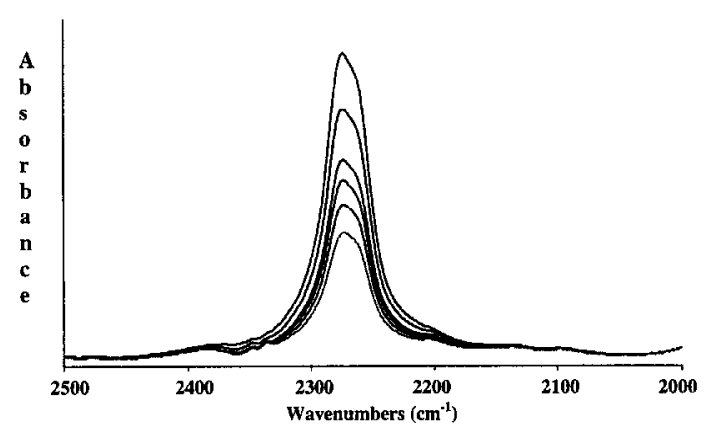

Fig. 1. Typical evolution of the NCO band with reaction time for an experiment involving suberin and HMDI.

which leads to the classical integrated expression:

$1 /[\mathrm{NCO}]-1 /[\mathrm{NCO}]_{0}=k_{2} t$

If the Lambert-Beer law is applied to the variation of the intensity of the NCO peak around $2250 \mathrm{~cm}^{-1}$ as a function of the reaction time, the following relationship can be written:

$\left(A_{0}-A\right) / A=k_{2}[\mathrm{NCO}] t$

where $A$ stands for optical density.

The progressive decrease of the FTIR NCO peak with time was carefully monitored for each reaction, as shown in the typical example of Fig. 1 and the data thus, acquired processed according the second-order criteria discussed above. With both model condensations and polymerizations, the linearity of the second-order plots was always good up to about $55 \%$ and reached $90 \%$ in some cases. In all instances, a deviation was observed at higher conversion and this behaviour was more

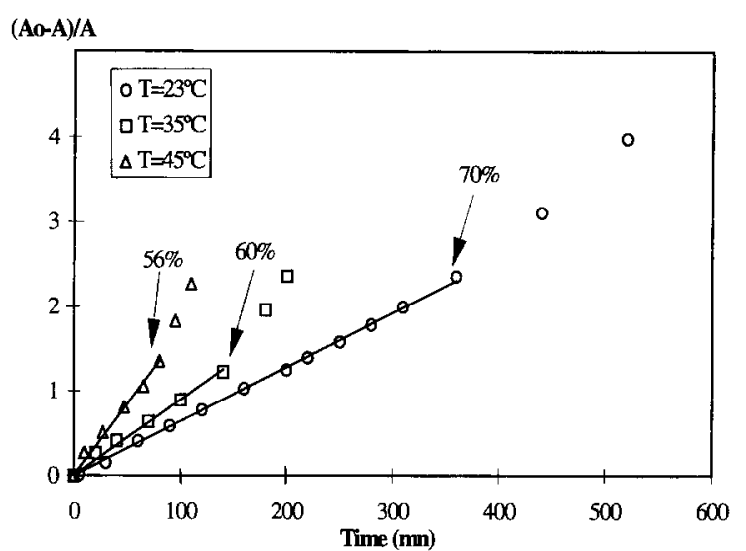

Fig. 2. Second-order plots for the reaction of suberin with HMDI in THF/DBTD solution at different temperatures, $[\mathrm{NCO}]_{0}=[\mathrm{OH}]_{0}=0.2 \mathrm{M}$. Note the yield at which a positive deviation begins.

pronounced when the reaction temperature was increased, as shown in Table 1 and Fig. 2. This phenomenon has been reported in the past with other polyurethane syntheses (Anzuino et al., 1975; Hager and Ueberreiter, 1979; Boufi et al., 1993) and was attributed to an autocatalytic effect induced by the urethane functions or, alternatively, to the consumption of NCO by side reactions like the formation of allophanates.

\subsection{Mono-isocyanates and symmetric di-isocyanates}

The second-order rate constants for the uncatalyzed stoichiometric reactions between suberin

Table 1

Second-order rate constants and activation energies for reactions between suberin and different isocyanates at different temperatures in THF/DBTD solution

\begin{tabular}{lllll}
\hline Isocyanates & Temperature $\left({ }^{\circ} \mathrm{C}\right)$ & $10^{4} \mathrm{k}(1 / \mathrm{mol}$ per s) & Domain of validity $(\%)$ & $\mathrm{E}_{\mathrm{a}}(\mathrm{kJ} / \mathrm{mol})$ \\
\hline Phenyl & 23 & 16.3 & 86 & 18.7 \\
& 35 & 22.8 & 81 & \\
MDI & 45 & 27.5 & 55 \\
$n$-butyl & 23 & 16.1 & 80 & \\
HMDI & 23 & 5.75 & 76 \\
& 23 & 5.2 & 70 & 30.6 \\
& 35 & 6.6 & 56 & \\
\hline
\end{tabular}

MDI, diphenylmethane diisocyanate; HMDI, hexamethylene diisocyanate. 
and $\mathrm{Ph}-\mathrm{NCO}$ or $n \mathrm{Bu}-\mathrm{NCO}$ in THF at room temperature, were $1.510^{-4}$ and $0.2510^{-4} 1 / \mathrm{mol}$ per $\mathrm{s}$, respectively. The modest reactivity of the aliphatic isocyanate compared with that of aromatic homologues is well documented and the present quantitative difference agrees with that reported in previous studies (Entelis and Nesterov, 1966; Belgacem et al., 1989, 1993). The catalyzed reactions gave a smaller difference in reactivity, as shown in Table 1 .

\subsection{Asymmetric di-isocyanates}

The kinetic behaviour of asymmetric diisocyanates was treated according to the competitive consecutive second-order model applied by Frost and Schwemer (1952) to the saponification of diesters and later adapted by Burkus and Eckert (1958) to the reaction of toluene 2,4-diisocyanate (2,4-TDI). Two rate constants were determined, corresponding respectively to the reaction of the $\mathrm{NCO}$ groups at the para $(B)$ and ortho $(C)$ positions, viz:

$$
\begin{aligned}
& A+B \stackrel{k_{\mathrm{a}}}{\rightarrow} C \\
& C+A \stackrel{k_{\mathrm{b}}}{\rightarrow} D \\
& -\mathrm{d}[A] / \mathrm{d} t=k_{\mathrm{a}}[A][B]+k_{\mathrm{b}}[A][C] \\
& \quad-\mathrm{d}[B] / \mathrm{d} t=k_{\mathrm{a}}[A][B]
\end{aligned}
$$

Whereas 2,4-TDI is an intrinsically asymmmetric diisocyanate which always displays two distinct rate constants for the reaction of each functional group, 2,6-TDI is symmetric in terms of chemical structure, but can become 'asymmetric' after one of its NCO group has reacted, i.e. the formation of the urethane moiety can alter the reactivity of the remaining $\mathrm{NCO}$ group. This

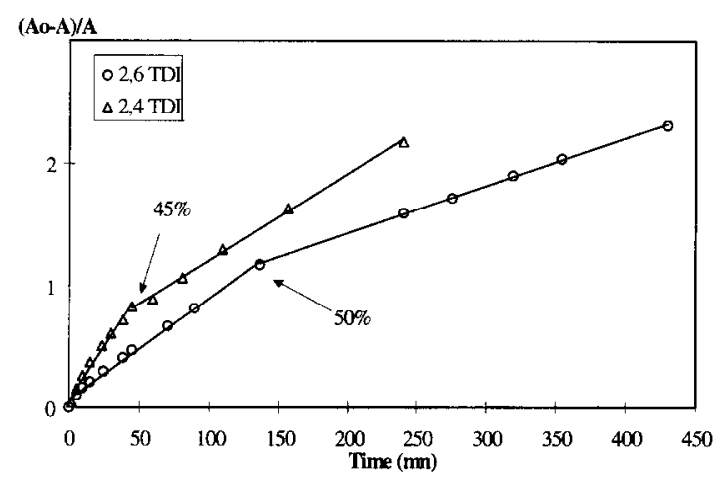

Fig. 3. Second-order plot for the reaction of 2.4- and 2.6-TDI with suberin in THF/DBTD solution.

secms particularly relevant in the present context, because the condensation with a side $\mathrm{OH}$ function on the suberin chain introduces steric problems for the reaction of the second NCO of 2,6-TDI. Thus, our terminology, referring to rate constants, can be visualized as follows with the two TDIs:

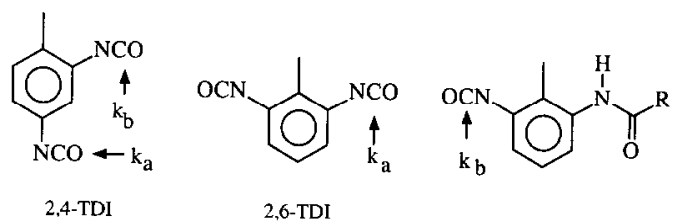

It seems logical to use this approach, because the second-order plots of the reaction of both diisocyanates gave two straight lines with a break in the slope, as shown in Fig. 3. This break occurred at about $50 \%$ conversion and indicated that one of the NCO functions was more reactive than the other, irrespective of the TDI used. Table

\begin{tabular}{|c|c|c|c|c|c|c|c|c|}
\hline 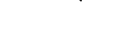 & \multicolumn{4}{|c|}{ Frost and Schwemer model } & \multicolumn{4}{|c|}{ Graphic data } \\
\hline & $10^{4} k_{\mathrm{a}}$ & $10^{4} k_{\mathrm{b}}$ & $k_{\mathrm{a}} / k_{\mathrm{b}}$ & $10^{4}\left(k_{\mathrm{a}}+k_{\mathrm{b}}\right)$ & Slope 1 & Slope 2 & $1 / 2$ & $1+2$ \\
\hline 2,4 TDI & 18.1 & 2.1 & 8.6 & 20.2 & 15.3 & 6.7 & 2.3 & 22.0 \\
\hline $2,6 \mathrm{TDI}$ & 11.1 & 1.4 & 7.9 & 12.5 & 6.9 & 3.3 & 2.1 & 10.2 \\
\hline
\end{tabular}
2 gives the second-order rate constants and the

Table 2

Second-order rate constants and slopes of the straight lines for the reactions shown in Fig. 3

Data are expressed as $1 / \mathrm{mol}$ per $\mathrm{s}$ 
values of the two slopes, as measured from Fig. 3 for the reaction of suberin with 2,4- and 2,6-TDI, respectively. With both isocyanates, $k_{\mathrm{a}} / k_{\mathrm{b}}$ turned out to be about 8 , a figure already reported in the literature for the 2,4 isomer (Burkus and Eckert, 1958; Belgacem et al., 1993).

The values of slopes 1 and 2, determined graphically, are not directly related to the individual rate constants, which are instead provided by the Frost-Schwemer treatment. However, the sum of the two slopes must be the same as the sum of $k_{\mathrm{a}}$ and $k_{\mathrm{b}}$, as was indeed the case here (Table 2).

\section{Conclusion}

The results obtained in this kinetic study, involving both model reactions and polycondensations of suberin with isocyanates, showed that the former natural macromolecule behaves in a straightforward manner in this specific context. The fact that no anomalies were detected opens the way to an investigation of the macromolecular syntheses with a good knowledge of the basic features. This work is in progress.

\section{Acknowledgements}

The authors wish to thank the French-Portuguese Scientific Cooperation Program and JNICT Portugal for financial support and the Champcork Company for the cork samples.

\section{References}

Agullô, C. and Seone, E., 1981. Free hydroxy groups in the cork suberin. Chem. Ind., 608-609.

Agullô, C. and Seone, E., 1982. Hydrogenolisis de la suberina del corcho con $\mathrm{LiBH}_{4}$; grupos carboxilo libres. An. Quim., 78: 389-393.

Anzuino, G., Pirro, A., Rossi, O. and Friz, L.P., 1975. Reaction of diisocyanates with alcohols. I. Uncatalyzed reactions. J. Polym. Sci. Polym. Chem. Ed., 13: 1657-1666.
Arno, M., Serra, M.C. and Seone, E., 1981. Metanolisis de la suberina del corcho. Identificacion y estimacion de sus componentes acidos, como esteres metilicos. An. Quim., 77: $82-86$.

Belgacem, M.N., Quillerou, J., Gandini, A., Rivero, J. and Roux, G., 1989. Urethanes and polyurethanes bearing furan moieties-2. Comparative kinetics of the formation of furanic and other monourethanes. Eur. Polym. J., 25: 1125-1130.

Belgacem, M.N., Quillerou, J. and Gandini, A., 1993. Urethanes and polyurethanes bearing furan moieties-3. Synthesis, characterization and comparative kinetics of the formation of diurethanes. Eur. Polym. J., 29: 1217-1224.

Boufi, S., Belgacem, M.N., Quillerou, J. and Gandini, A., 1993. Urethanes and polyurethanes bearing furan moieties-4. Synthesis, kinetics and characterization of linear polyurcthancs. Macromolccules, 26: 6706-6717.

Burkus, J. and Eckert, C.F., 1958. The kinetics of the triethyamine-catalyzed reaction of diisocyanates with 1-butanol in toluene. J. Am. Chem. Soc., 80: 5948-5950.

Cordeiro et al., 1997. Submitted.

Entelis, S.G. and Nesterov, O.V., 1966. Kinetics and mechanism of the reactions of isocyanates with compounds containing 'active' hydrogen. Russ. Chem. Rev., 35: 917-930.

Fontan Yanes, J. and Garzon Sanchez, R., 1961. Preparacion de polimeros a partir de acidos del corcho. An. Fis. Quim., 107(B): 541-552; Ynfiesta, J., Fontan Yanes, J. and Navarro Beato, J., 1961., Peparacion de copoliesteres no saturados. An. Fis. Quim., 107(B): 431-440.

Frost, A.A., Schwemer, W.C., 1952. The kinetics of competitive cosecutive second order reactions: The saponification of ethyl adipate and of ethyl succinate. J. Am. Chem. Soc., 74: $1268-1273$.

Gandini, A., 1992. Polymers from renewable resources. In: S.L. Aggarwal and S. Russo (Editors), Comprehensive Polymer Science, First Supplement. Pergamon Press, Oxford, pp. 527-573.

Hager, W. and Ueberreiter, K., 1979. Uber die kinetik der reacktion von hexamethylendiisocyanat mit 2-ethyl-1,3hexandiol in verschiedenen Lösungsmitteln. Makromol. Chem., 180: 939-948.

Holloway, P.J., 1972. The composition of suberin from the corks of Quercus suber $L$. and Betula pendula roth. Chem. Phys. Lipids, 9: 158-170.

Kolattukudy, P.E., 1978. Chemistry and biochemistry of the aliphatic components of suberin. In: Kahl, G. (Editor), Biochemistry of Wounded Plant Tissues. Walter Gruyter and Co., Berlin, pp. 43-84.

Pereira, H., 1988. Chemical composition and variability of the cork of Quercus suber L. Wood Sci. Technol. 22: 211-218. 